\title{
Irradiation resistance, microstructure and mechanical properties of nanostructured (TiZrHfVNbTa)N coatings
}

\author{
Alexander D. Pogrebnjak a, e, Ivan V. Yakushchenko a, Oleksandr V. Bondar a, \\ Vyacheslav M. Beresnev ${ }^{\mathrm{b}}$, Keiji Oyoshi ${ }^{\mathrm{c}}$, Orest M. Ivasishin ${ }^{\mathrm{d}}$, Hiroshi Amekura ${ }^{\mathrm{c}}$, \\ Yoshihiko Takeda ${ }^{\mathrm{c}}$, Marek Opielak ${ }^{\mathrm{e}, ~ *}$, Czeslaw Kozak ${ }^{\mathrm{f}}$ \\ a Sumy State University, Sumy, Ukraine \\ ${ }^{\mathrm{b}}$ Karazin National University, Kharkiv, Ukraine

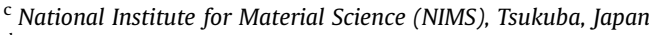 \\ ${ }^{\mathrm{d}}$ V. Kurdyumov Institute for Metal Physics, NAS of Ukraine, Kiev, Ukraine \\ e Institute of Transport, Combustion Engines and Ecology, Lublin University of Technology, 20-618 Lublin, Poland \\ ${ }^{\mathrm{f}}$ Department of Electrical Devices and High Voltage Technology, Lublin University of Technology, 20-618 Lublin, Poland
}

\section{A R T I C L E I N F O}

\section{Article history:}

Received 13 August 2015

Received in revised form

2 March 2016

Accepted 6 April 2016

Available online 8 April 2016

\section{Keywords:}

Nitrides of high-entropy alloys

Microstructure

Wear

Mechanical properties

$\mathrm{Au}^{-}$implantation

Irradiation resistance

\begin{abstract}
A B S T R A C T
Nitrides of high-entropy alloys (TiHfZrNbVTa)N were fabricated using cathodic-vacuum-arc-vapordeposition method. Morphology and topology of the surface of the coatings, roughness, elemental and phase composition, microstructure and mechanical properties were investigated. Dependence of deposition parameters on surface morphology and elemental composition was demonstrated. Influence of the heavy negative charged $\mathrm{Au}^{-}$ions implantation on phase structure, microstructure and hardness of nitride (TiHfZrNbVTa)N coatings was investigated.
\end{abstract}

() 2016 Elsevier B.V. All rights reserved.

\section{Introduction}

New classes of high-entropy alloys, which consist of at least 5 main elements with corresponding atomic concentrations $5 \div 35$ at.\%, are under great interest in modern material science [1-3]. One-phase stable substitutional solid solution with FCC or BCC lattice is usually formed in such high-entropy alloys, and this is the reason for further investigations. This solid solution is either thermodynamically stable or high-strength [4-15]. Formation of nitrides and carbides from high-entropy alloys is also an actual task of modern material science, because such materials have much more higher wear, corrosion and oxidation resistance, higher hardness and plasticity in comparison with pure high-entropy alloys [16-24]. It is also very important to explore the limits of resistance of high-entropy alloys nitrides to implantation by high-

\footnotetext{
* Corresponding author.

E-mail address: m.opielak@pollub.pl (M. Opielak).
}

energy atoms. For this purpose, we have selected negative $\mathrm{Au}^{-}$ ions (with $1 \times 10^{17} \mathrm{~cm}^{-2}$ dose and $60 \mathrm{keV}$ kinetic energy), because they are easier to identify using RBS or PIXE methods of analysis, and such components of the coatings as $\mathrm{Ti}, \mathrm{Zr}, \mathrm{Hf}, \mathrm{Nb}$ and $\mathrm{Ta}$ do not react with gold to form intermetallics [25-31].

\section{Experimental details}

Cathodes from high entropy alloys of the Ti-Zr-Hf-V-Nb-Ta system were produced by vacuum-arc melting in the atmosphere of high purity argon using a nonconsumable electrode into a water-cooled copper vessel. To fabricate a homogeneous composition of the alloy, the ingots were 6-7 times remelted.

Nitride coatings were deposited by vacuum-arc evaporation of a cathode [32-35] in a Bulat-3T-M device [36]. Deposition parameters and elemental composition of cathode and nitride coatings are presented in Table 1 , where $I_{a}-$ arc current, $I_{f}$ - focusing current, $\mathrm{U}_{\mathrm{b}}$ - bias voltage, $\mathrm{P}$ - pressure in the deposition chamber. 
Table 1

Deposition parameters and concentration of nitride coatings (TiZrHfVNbTa)N (1-7) and cathode TiZrHfVNbTa (8).

\begin{tabular}{|c|c|c|c|c|c|c|c|c|c|c|c|c|}
\hline \multirow[t]{2}{*}{ Series, no. } & \multirow[t]{2}{*}{ Ia, A } & \multirow[t]{2}{*}{$\mathrm{I}_{\mathrm{f}}, \mathrm{A}$} & \multirow[t]{2}{*}{$\mathrm{U}_{\mathrm{b}}, \mathrm{V}$} & \multirow[t]{2}{*}{ P, Torr } & \multicolumn{8}{|c|}{ Concentration, at.\% } \\
\hline & & & & & $\mathrm{N}$ & $\mathrm{Ti}$ & $\mathrm{Zr}$ & $\mathrm{Hf}$ & V & $\mathrm{Nb}$ & $\mathrm{Ta}$ & $\mathrm{Au}$ \\
\hline 1 & 110 & 0.4 & -150 & $3 \times 10^{-3}$ & 54 & 7.03 & 8.52 & 11.30 & 5.02 & 9.93 & 4.20 & 2.2 \\
\hline 2 & 110 & 0.4 & -150 & $3 \times 10^{-4}$ & 46 & 9.04 & 9.80 & 12.81 & 5.60 & 12.13 & 4.62 & 2.1 \\
\hline 3 & 110 & 0.4 & -150 & $7 \times 10^{-4}$ & 53 & 9.72 & 8.44 & 9.42 & 6.54 & 8.1 & 4.78 & \\
\hline 4 & 95 & 0.5 & -70 & $7 \times 10^{-4}$ & 36 & 16.60 & 16.85 & 8.79 & 6.95 & 9.92 & 4.89 & \\
\hline 5 & 95 & 0.5 & -70 & $4 \times 10^{-3}$ & 55 & 10.76 & 7.71 & 8.06 & 5.85 & 8.38 & 4.24 & \\
\hline 6 & 100 & 0.45 & -70 & $5.2 \times 10^{-3}$ & 55 & 6.96 & 8.42 & 9.33 & 6.23 & 7.82 & 4.04 & \\
\hline 7 & 95 & 0.5 & -70 & $0.5 \times 10^{-4}$ & 22 & 14.65 & 15.15 & 15.35 & 9.75 & 13.75 & 7.25 & \\
\hline 8 & - & - & - & - & - & 21.52 & 18.77 & 15.5 & 10.2 & 18.2 & 15.81 & \\
\hline
\end{tabular}

Impulse mode of deposition was selected to increase the energy of ion-plasma flow, improve adhesion of deposited coatings to substrate, and to obtain more dispersive structure of coatings [37]. A 570 Grade 36 steel disks with $45 \mathrm{~mm}$ diameter and $4 \mathrm{~mm}$ thickness were used as substrates. Thickness of deposited coatings was evaluated using scanning electron microscopy on cross-sections, and it was $5.6 \div 5.9 \mu \mathrm{m}$. Analysis of elemental composition of the coatings showed, that increasing of working gas pressure from
$3 \times 10^{-4}$ до $5.2 \times 10^{-3}$ Torr leads to significant increasing of nitrogen concentration, and decreasing of $\mathrm{Ti}, \mathrm{Nb}$ and $\mathrm{V}$. It can be explained by resputtering of heavy atoms by more intense plasma flow during deposition. Also, additional analysis of coating using RBS and PIXE allowed to define concentration of $\mathrm{Au}$ in the implanted series. It was approximately equal to 2.1 at.\%.

The structure and phase composition of nitride coatings were analyzed using X-ray diffraction in $\mathrm{Cu}-\mathrm{K} \alpha$ radiation (DRON 3M), and
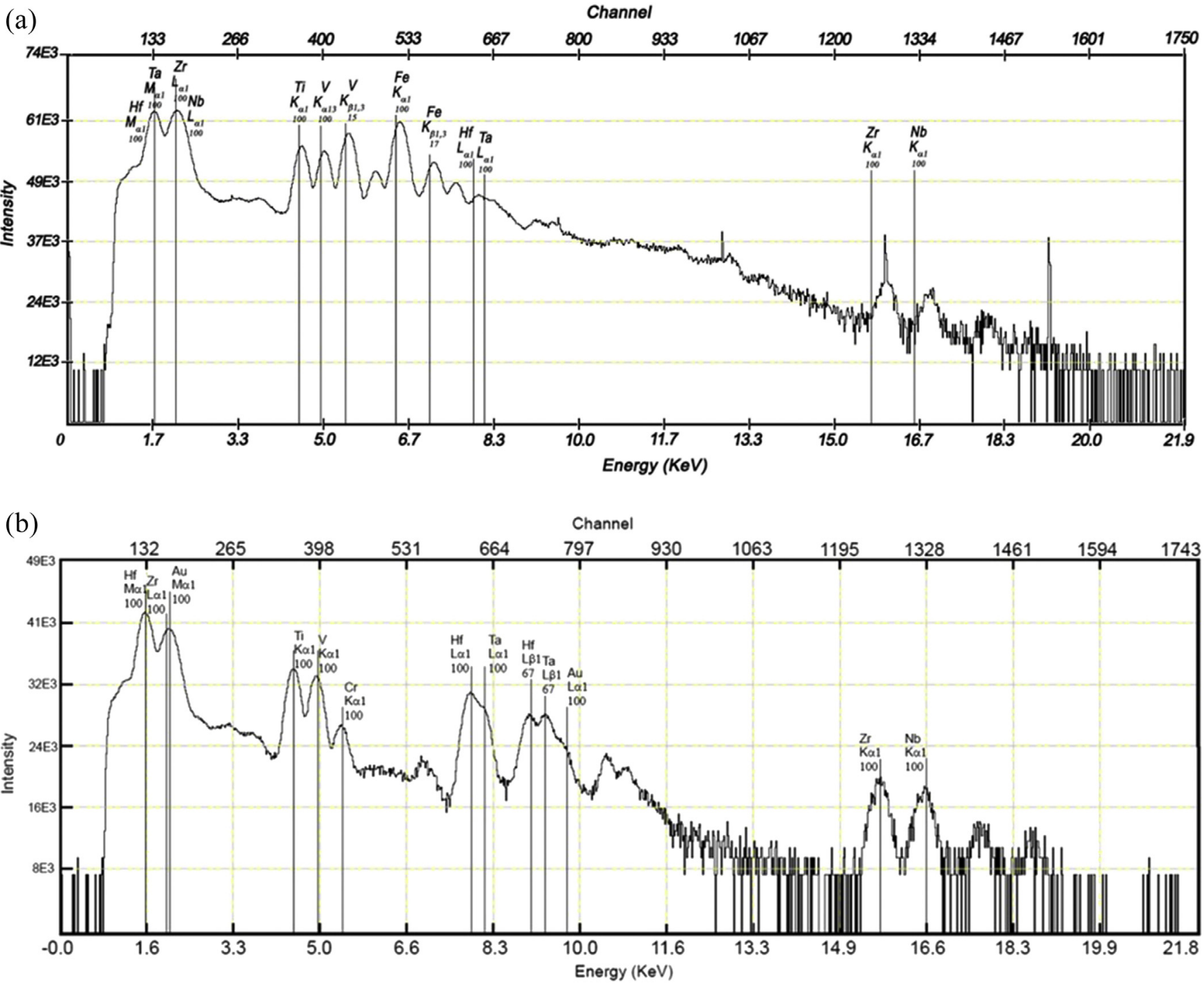

Fig. 1. Integral PIXE spectrum, taken from samples from Series 1 (a) and 2 (b) upon irradiation by a proton microbeam (1.4 MeV). 

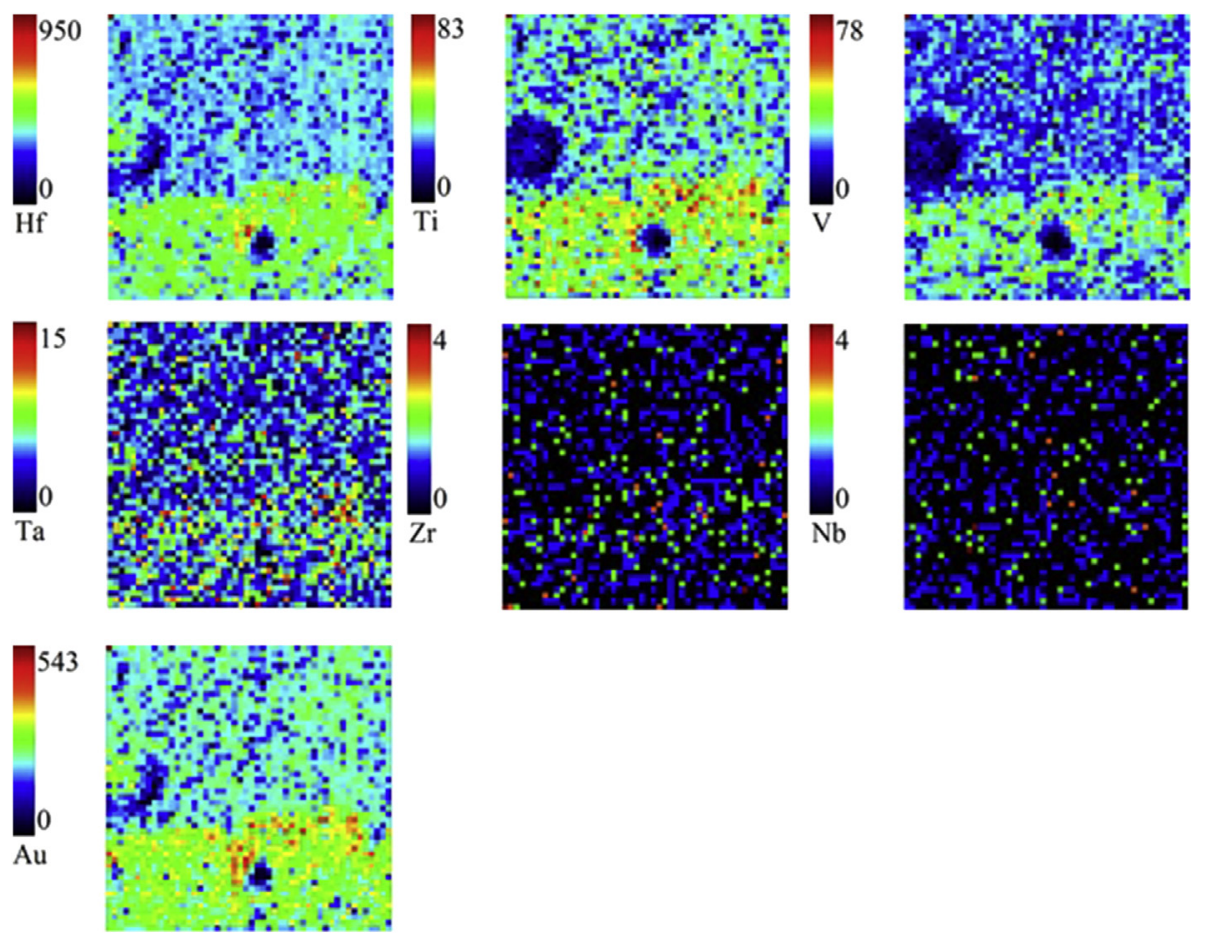

Fig. 2. PIXE maps of elements distribution on the coating's surface, Series 2.

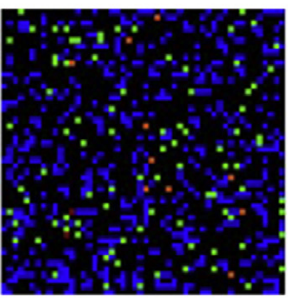

$\mathrm{Cr}-\mathrm{K} \alpha$ radiation (RINT-2500 V, Japan). Working values of voltage and current were $40 \mathrm{kV}$ and $300 \mathrm{~mA}$, respectively. The measurements were done under $3^{\circ}, 10^{\circ}, 30^{\circ}$ for the series in the initial state (as deposited state), and under $2^{\circ}$ for the series after ion implantation. It was done in order to decrease the thickness of analyzed layer, as well as to analyze the implanted layer more precisely.

Elemental composition was investigated using energydispersive spectroscopy (SEM with EDX). For this purpose EDX analysis and ToF-SIMS analysis (ULVAC-PHI TRIFT V nanoTOF, Physical Electronics, Inc., Japan) were used.

Morphology of the coating's surface was studied using scanning electron microscopy (SEM) methods. Therefore, JEOL-7000F (Japan) and scanning probe microscope SPI 3800N, Seiko Instruments Inc, USA, were used.

In depth elemental analysis was performed by Rutherford backscattering spectroscopy (RBS) using $\mathrm{He}^{+}$ions with an energy of

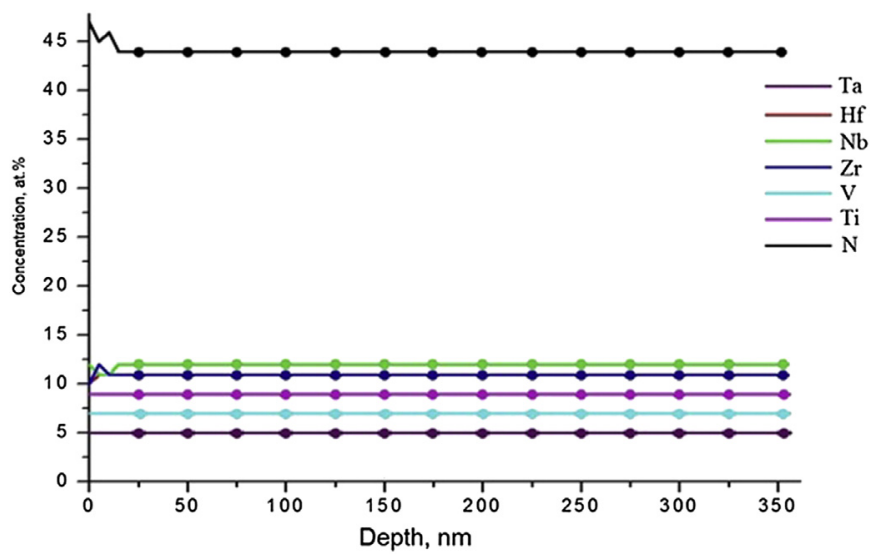

Fig. 3. Distribution of elements in the surface layer of the sample from Series 2, based on RBS measurements.
$1 \mathrm{MeV}$ (the scattering angle $\theta=170^{\circ}$ upon the normal incidence of the probing ions onto the samples). The detector had an energy resolution of $16 \mathrm{keV}$; the dose of helium ions was $5 \mu \mathrm{Ci}$. The processing of the RBS spectra and of the in depth profiles of the elemental distribution was carried out using a standard software.

Such mechanical properties as hardness and elastic modulus were studied using REVERTEST device (Switzerland) for microhardness measurements, and Triboindentor TI-950 (HYSITRON Inc.) for measurements of nanohardness and elastic modulus. The hardness of coatings was studied using DM- 8 hardness meter. In order to reduce the influence of the drop fraction (roughness), as well as to increase the accuracy of measurements, several coatings were polished after deposition.

The investigation of the wear resistance of multicomponent coatings was done using tribometry methods on an automated friction machine (Tribometer, CSM Instruments). An $\mathrm{Al}_{2} \mathrm{O}_{3}$ ball with a $6.0 \mathrm{~mm}$ diameter was used as a counterbody. Using optical and scanning electron microscopy (NanoScan 450), the peculiar properties of the wear of the samples and the counterbody were investigated. The measurement of the vertical section of wear grooves on the sample were performed using a profilometer in four diametrically and orthogonally opposite regions, and the mean values of groove section area as well as its depth were determined.

High-resolution transmission electron microscopy (HRTEM) was used to investigate microstructure of the coatings after ion implantation in the surface layer and in the depth of the coatings. Analysis was done using JEOL JEM-2100F with electron energy up to $200 \mathrm{keV}$.

Ion implantation by negative $\mathrm{Au}^{-}$ions with $60 \mathrm{keV}$ energy was provided. The dose of $10^{17}$ ions $/ \mathrm{cm}^{2}$ was used. Negative $\mathrm{Au}^{-}$ions were generated by a Cs-assisted heavy-ion source of plasmasputter type, with a cusp magnetic field. Projective ion path of $\mathrm{Au}^{-}$ions $R_{\mathrm{p}} \approx 34 \mathrm{~nm}$. 


\section{Results and discussions}

\subsection{Elemental composition}

Fig. $1 \mathrm{a}-\mathrm{b}$ shows the results of PIXE analysis for Series 1 and 2 . Studying these spectra with the integrated concentration over the depth of analysis, we found all the elements constituting the investigated coatings. Presence of $\mathrm{Cr}$ in Fig. $1 \mathrm{~b}$ can be explained by probably misinterpreting of obtained data, because $\mathrm{Cr}$ is close to $\mathrm{V}$ in the periodic table (they have almost equal atomic mass).

Fig. 2 shows maps of distribution of elements on the coating's surface for Series 1 . The surface area is non-uniform, it is depleted on $\mathrm{Zr}$ and $\mathrm{Nb}$, microdroplets on the surface consisting predominantly of heavier elements Ta and Hf. However, as it follows from SEM analysis, there is no strict dependence of deposition parameters on elemental composition of droplet fractions. The layer of the implanted $\mathrm{Au}^{-}$ions has an approximate concentration equal to $2.1 \%$ due to results of EDS analysis. The thickness of the implanted layer is approximately around $20 \mathrm{~nm}$, but the lower border of the layer is very unclear and spread, which is rather typical for implanted layers.

In order to investigate distribution of the elements over the depth of the coatings, RBS was conducted. The distribution of elements in the sample from Series 3 is presented on the Fig. 3. As it is seen, some non-uniformity is observed in the sub-surface layer, up to $15 \mathrm{~nm}$, and afterward elements are distributed evenly on the all analyzed depth (up to $375 \mathrm{~nm}$ ).

Investigation of the coating's cross-section (sample from Series 3 ) gives more detailed information regarding coatings thickness and its elemental composition, see Fig. 4. It is clearly seen, that coating's thickness is around $6.5 \div 6.9 \mu \mathrm{m}$, all consistent elements are observed.

However, in order to investigate the influence of ion implantation on microstructure and properties of investigated high-entropy nitride coatings (TiZrHfVNbTa)N, HRTEM investigation were provided.

\subsection{Microstructure and phase composition}

The XRD patterns of investigated high-entropy alloys are presented on the Fig. 5. We can see, that phase with FCC crystal lattice was formed as the dominant crystalline phase (under higher values of working gas pressure). As it is supported by previous investigations [38-42], this phase is rather typical for nitrides of high-entropy alloys. Anyway, two crystalline phases are clearly seen: FCC (dominant, as it was mentioned before), and BCC. BCC ratio is the biggest for coatings, fabricated in low-vacuum conditions. Increasing of $\mathrm{N}_{2}$ pressure lead to alignment of FCC and BCC ratio, like 1 to 1 . In addition, for crystalline structure, this ratio was 3 to 1, respectively. The largest sizes of crystallines of FCC phase were
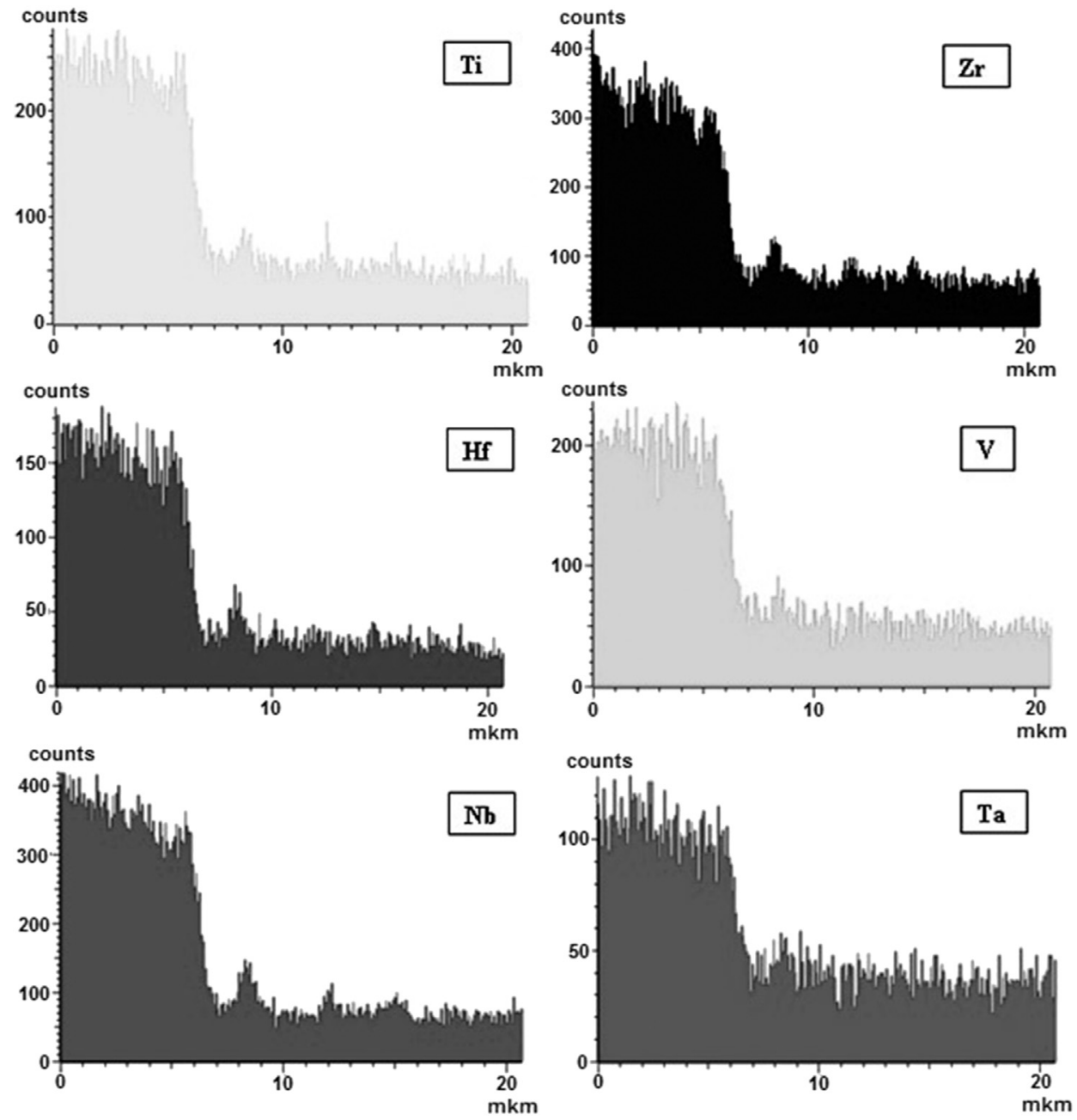

Fig. 4. EDS microanalysis of elemental composition on cross-section of the sample from Series 3. 
17-20 nm, for samples from Series 1. On the Fig. 5b we can see the diffraction pattern, obtained under $10^{\circ}$ (informative layer thickness in this case was $0.5 \mu \mathrm{m}$ ), and $2^{\circ}$ (informative layer decreases to $70 \mathrm{~nm}$ ). It is obviously seen, that implantation of low-energy negative $\mathrm{Au}^{-}$ions with $1 \times 10^{17} \mathrm{~cm}^{-2}$ dose lead to disordering of the crystalline structure, and also lead to formation of polycrystalline structure without preferred orientation. Average size of crystallines after ion implantation decreased to $5 \mathrm{~nm}$ (in the layer of projective ion penetration path of $34 \mathrm{~nm}$ ).

On the Fig. 6a the cross-section of the (TiHfZrNbVTa)N coating (sample from Series 2), implanted by $\mathrm{Au}^{-}$ions, is demonstrated. The surface layer with the thickness of the projective ion path $\mathrm{Rp} \approx 34 \mathrm{~nm}$ is disordered and has mixed amorphousnanocrystalline structure. Lines on the Fig. $6 \mathrm{~b}$ show the different areas of investigations, and letters $\mathrm{A}-\mathrm{H}$ specifies the points, for which microdiffraction was obtained. Circles, marked by D, E and $\mathrm{H}$ (Fig. 6c-e) are given in higher magnification for better understanding; distances between the planes are indicated.

Surface layer (thickness around $30 \mathrm{~nm}$ ) is very disordered and has amorphous-crystalline structure with dominant amorphous structure. Nevertheless, on the border of projective $\mathrm{Au}^{-}$ion path, we can see clear crystalline structure on the Fig. 6b. Distance between crystalline planes is equal to $0.250 \mathrm{~nm}$ (plane (111)), and $0.221 \mathrm{~nm}$ (plane (200)). These data is a little different, than obtained by XRD analysis where interplanar spacing for planes (111) and (200) is equal to 0.257 and 0.225 , respectively. However, we should also consider that the depth of informative layer for XRD is much higher in this case $-70 \mathrm{~nm}$.

In addition, borders of nanograins can be clearly seen on HRTEM images (Fig. 6f). However, due to ballistic collisions of heavy $\mathrm{Au}^{-}$ ions, the average size of nanograins in the subsurface layer is significantly low $(0.8-1 \mathrm{~nm})$. Local areas of Au were detected by microdiffraction analysis - reflections of interplanar spacing of $0.197 \mathrm{~nm}$, which correspond to (200) plane. These areas were formed due to heavy-ion implantation.

In the depth of the coating, from 30 to $130 \mathrm{~nm}$, interplanar distance decreased to $0.255-0.259$ for (111) plane and to 0.226 for (200) plane. In the depth of $180 \mathrm{~nm}$ (zone $\mathrm{H}$ ) we detected planes with $0.275-0.278 \mathrm{~nm}$ interplanar spaces. This values correspond to interplanar spacing of HCP crystalline structure ((100) plane) of transition metals nitrides. In addition, HCP and FCC crystalline lattices are very close by their inner energy with relatively small barrier for transition from HCP to FCC, and vice versa. We can suggest, that, based of HRTEM results, a local area were formed in the investigated coatings, in which transition from FCC to HCP lattice by shift mechanism took place. Low concentration of nitrogen atoms was the reason of such change (it caused instability of the crystalline cell), and, as a result, FCC lattice transformed into more thermodynamically stable HCP lattice.

The investigated (TiHfZrNbVTa)N coatings demonstrate higher resistivity to irradiation of negative ions $\mathrm{Au}^{-}$, than monocrystalls and classical polycrystalls [43]. The effectivity of defects recombination during relaxation processes is higher near cascades due to close interfaces in nanostructured materials. For the investigated coatings, grinding of nanograins to sizes $5-8 \mathrm{~nm}$ and less increased the ratio of interfaces (double and triple grain junctions, nanograins boundaries).

\subsection{Mechanical and tribotechnical properties}

One of the most important characteristics for the express analysis of mechanical properties of the coatings is hardness $[44,45]$. The measured hardness of the investigated (TiZrHfVNbTa) $\mathrm{N}$ coatings was $\mathrm{HV}_{0.2}=51 \mathrm{GPa}$ for Series $1, \mathrm{HV}_{0.2}=38 \mathrm{GPa}$ for Series 3 and mean value was $\mathrm{HV}_{0.2}=40 \mathrm{GPa}$ for coatings obtained at
$\mathrm{U}_{\mathrm{b}}=-70 \mathrm{~V}$ (series $4-7$ ).

Measurements of nanohardness $\mathrm{H}$ and reduced Young's modulus $\mathrm{Er}$ on the different coating's depth were done with discrete changing (increasing) of the load from $0.05 \mu \mathrm{N}$ to $10 \mu \mathrm{N}$. The period of load was equal to $3 \mathrm{~s}$, keeping of constant load for $0.5 \mathrm{~s}$, and unload for $3 \mathrm{~s}$. Curves of loading-unloading from contact depth $\mathrm{h}$ of indenter were built using the obtained data. The maximal penetration depth was $80 \mathrm{~nm}$. Such depth is less, than $10 \%$ of total coating thickness, thus, the influence of substrate on measured nanohardness is eliminated. The average values of nanohardness and reduced Young's modulus are presented in Table 2.

The dependencies of $\mathrm{H}$ and $\mathrm{Er}$ on contact depth $\mathrm{h}$, for the Series 5 (after implantation) are presented on the Fig. 7. We can see, that nanohardness is continuously growing to its maximum value $38.3 \mathrm{GPa}$ for the depth $19.3 \mathrm{~nm}$, and then is stable in range 36.3-37.7 GPa, with maximum $39 \mathrm{GPa}$ on the maximum analysis depth $67.34 \mathrm{~nm}$. It means, that increasing of hardness takes place in the implanted area, and furthermore.

As it was mentioned before, implantation of heavy negative $\mathrm{Au}^{-}$ ions lead to forming of amorphous-crystalline structure without preferred orientation of crystallines in the surface and subsurface layers. Nanograins were grinded, and ratio of interfaces was significantly increased. In addition, at the initial stages of implanted ions incorporation into the coating, crystallines with (200) plane orientation were destroyed, because of critical density of points

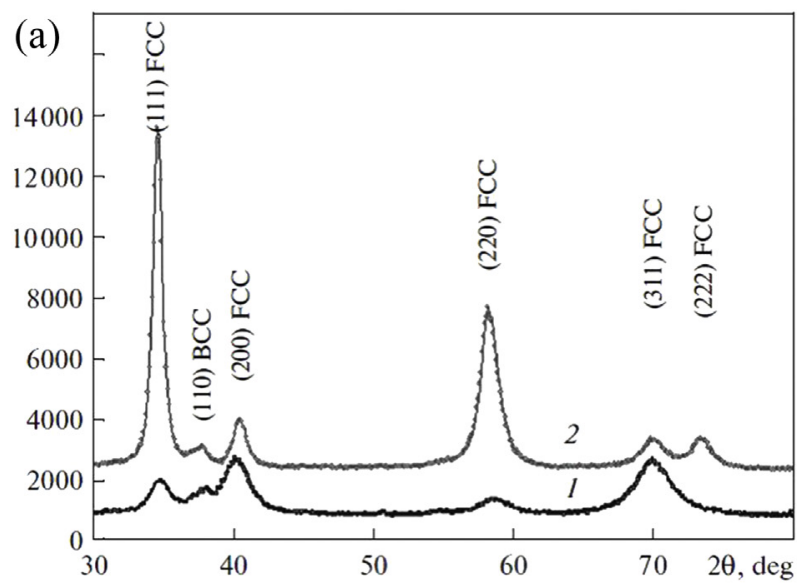

(b)

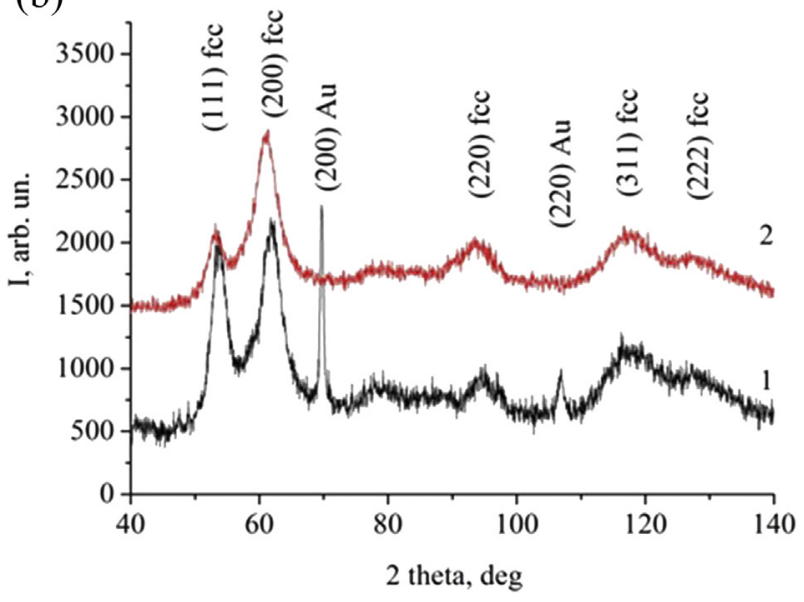

Fig. 5. XRD patterns of (TiZrHfVNbTa)N coatings, fabricated under different pressures (a): Series 2 (curve 1); Series 1 (curve 2). The pattern of the Series 2 after implantation by $\mathrm{Au}$ - ions under low angle analysis $2^{\circ}$ (curve 1 ) and under $10^{\circ}$ (curve 2 ) (b). 

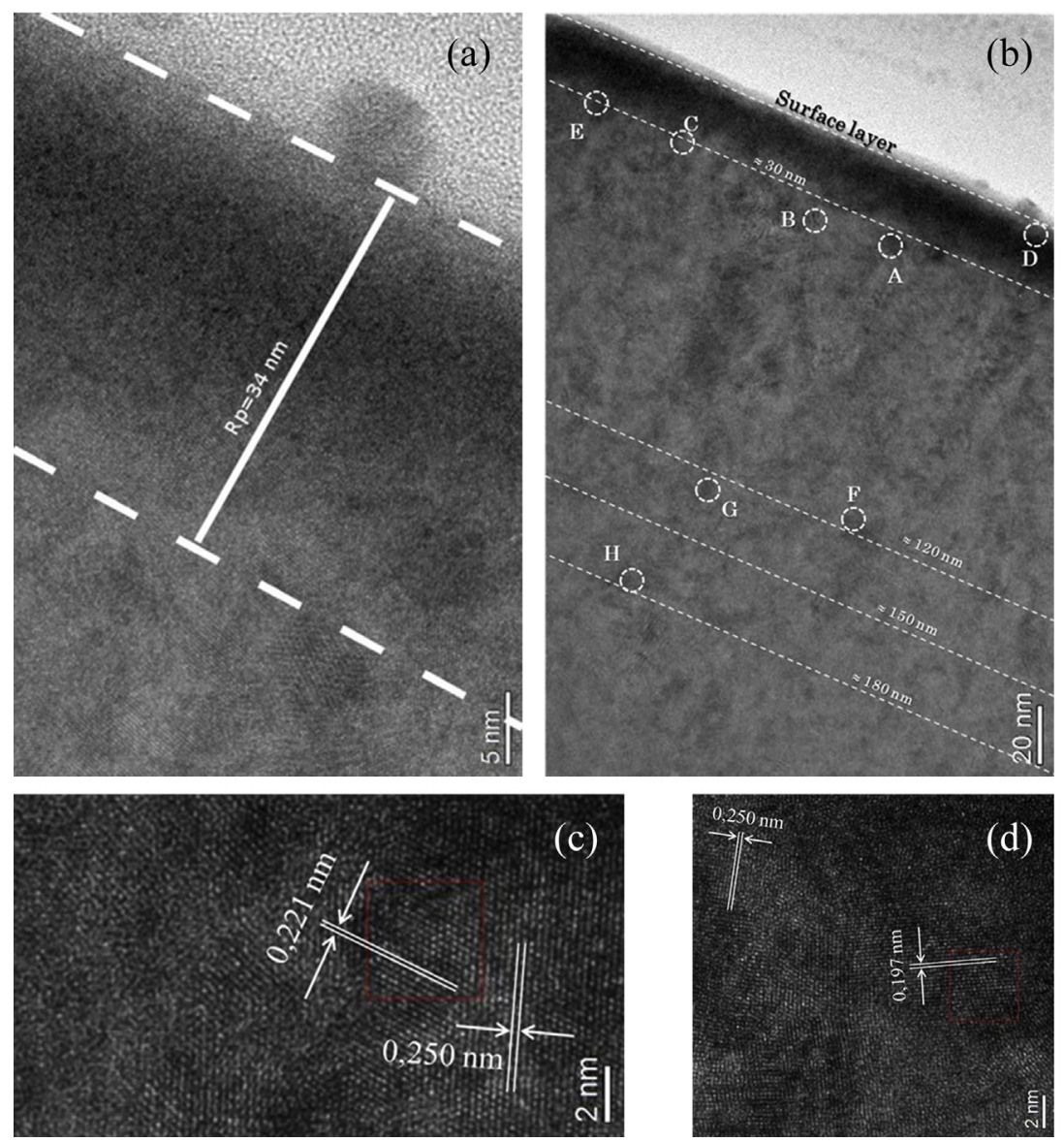

(b)
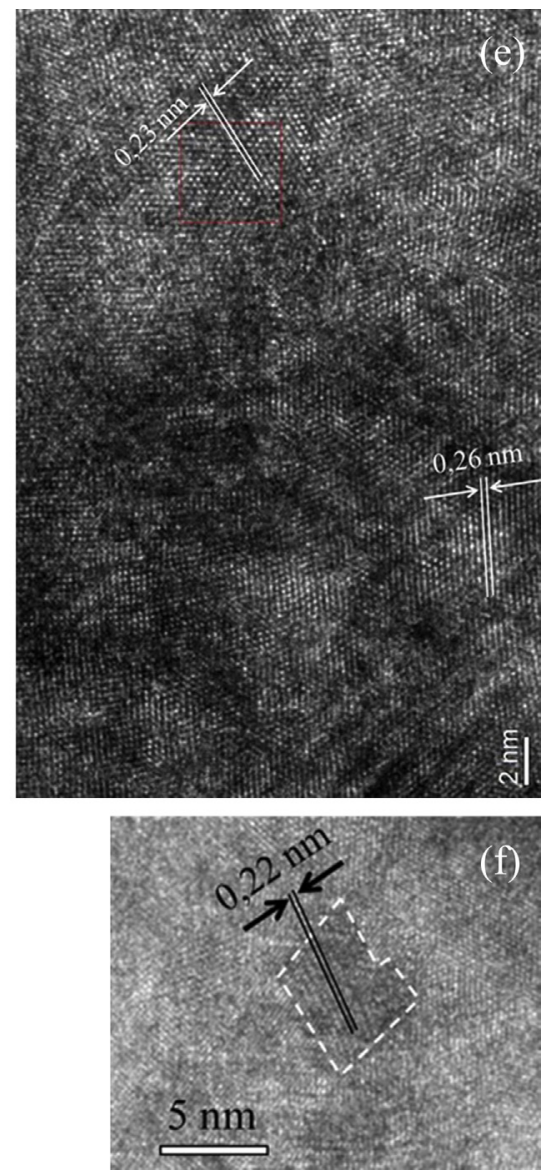

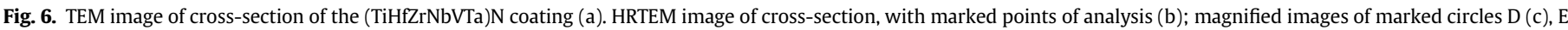
(d), H (e); part of the HRTEM image with marked nanograin (f).

Table 2

Results of investigation of mechanical properties of the (TiHfZrNbVTa)N coatings.

\begin{tabular}{llllll}
\hline Series no. & $\mathrm{H}, \mathrm{GPa}$ & $\mathrm{Er}, \mathrm{GPa}$ & $\mathrm{H} / \mathrm{Er}$ & $\mathrm{H}_{\max }, \mathrm{GPa}$ & $\mathrm{Er}_{\max }, \mathrm{GPa}$ \\
\hline 1 & 27.81 & 265.23 & 0.11 & 36.66 & 285.86 \\
2 & 34.22 & 278.14 & 0.12 & 39.05 & 296.85 \\
3 & 25.19 & 215.92 & 0.12 & 32.83 & 226.34 \\
4 & 28.68 & 267.07 & 0.11 & 45.32 & 313.67 \\
\hline
\end{tabular}

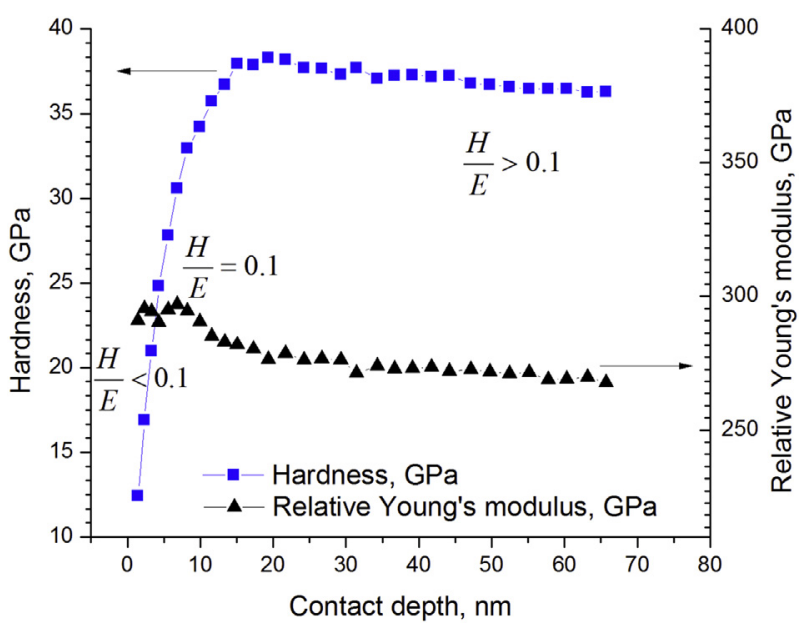

Fig. 7. Dependencies of nanohardness and reduced Young's modulus on contact depth for the samples from Series 2 . defects in these planes. In its turn, according to HRTEM data, significant grinding of nanograins was observed mostly in the region of direct ballistic collisions of nanograins and $\mathrm{Au}^{-}$ions. However, on the depth $20 \mathrm{~nm}$ and more, grains with sizes of 5-7 nm were observed. Thus, we can suppose, that during relaxation processes (after finishing of the collision phase) the following processes took place.

Structure, which was destroyed in the area of nanograins, oriented like (200) direction (in other words, this direction differs from the implanted ions direction), was restored while contacting with intact areas of the same grains. Epitaxial mechanism was the reason for the growth of the destroyed grains. As the evidence of such process, we can refer to the results of XRD analysis. Initially, in the subsurface of the non-implanted coatings, (200) orientation dominates for Series 2, but Series 1 demonstrates two predominate orientations - (111) and (200). However, the relative intensity of the (200) plane of Series 2 increased after ion implantation, as well as for Series 1, with the simultaneous decreasing of (111) plane intensity. Of course, it did not lead to formation of the structure in that area. But, increased level of stresses due to formation of defects in the implanted area (the possible contribute to dislocation defects could be done during relaxation, when grains were restored with some plane shifting at grains boundaries), and also decreasing of size of the grains became the reason for an advance of dislocations in the coating during plastic deformation. Which, in its turn, defines mechanical hardness of the material.

Thus, we can claim, that implantation of negative $\mathrm{Au}^{-}$ions led to increasing of nanohardness of the coatings. In addition, increasing 

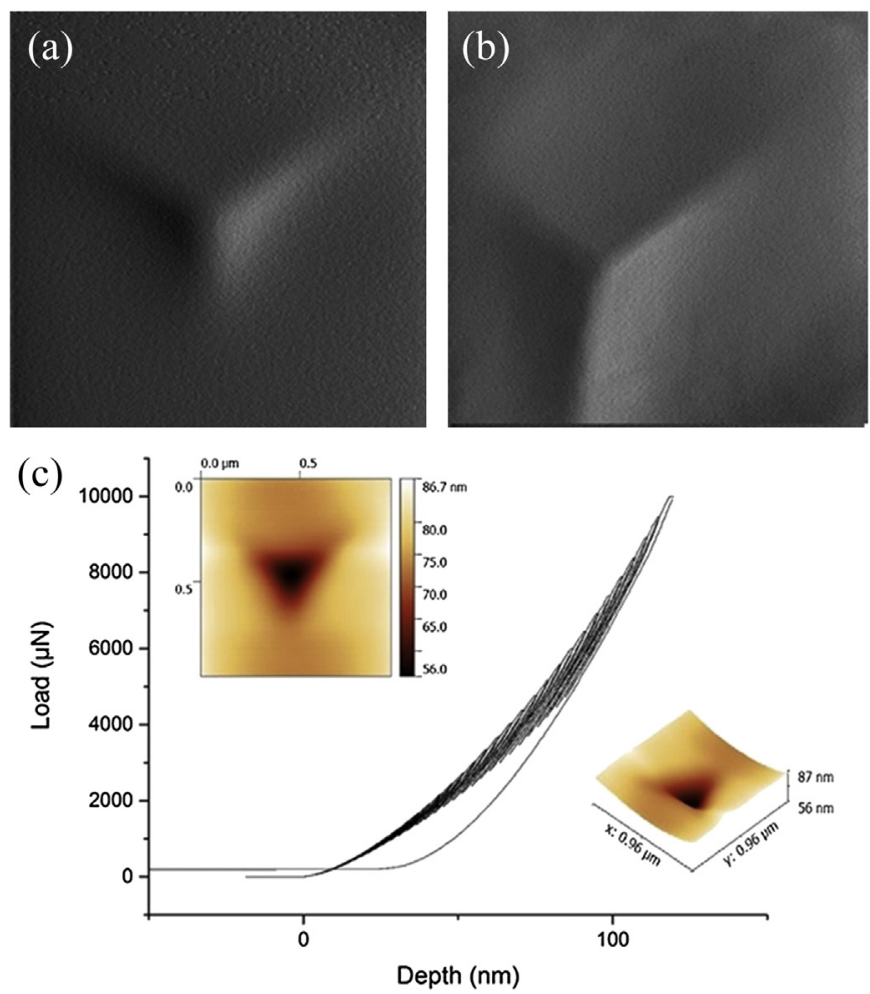

Fig. 8. AFM images of nanoindentor stamp in the coatings, samples from Series 5 (a) and Series 4 (b); results of mechanical investigations of the samples from Series 6 (c) indentation of the Berkovich pyramid under dynamic loading, 2D and 3D images of the stamp.

of plasticity index $\mathrm{H} / \mathrm{Er} \geq 0.1$ to the value of 0.15 was observed in the implanted series. As it follows from Refs. [45], H/Er ratio defines tribological characteristics of the coatings. Particularly, it showed the improved wear resistance of (TiHfZrNbVTa)N coatings.

Fig. $8 \mathrm{a}-\mathrm{b}$ shows the AFM images of nanoindentor stamp for Series 2 and Series 4 . As we can see, on the edges of the stamps there are no cracks for both series, so we can state that fabricated coatings are plastic enough, it correlates with values of $\mathrm{H} / \mathrm{Er}$ ratios. On the Fig. 8c we present the results of mechanical investigations of

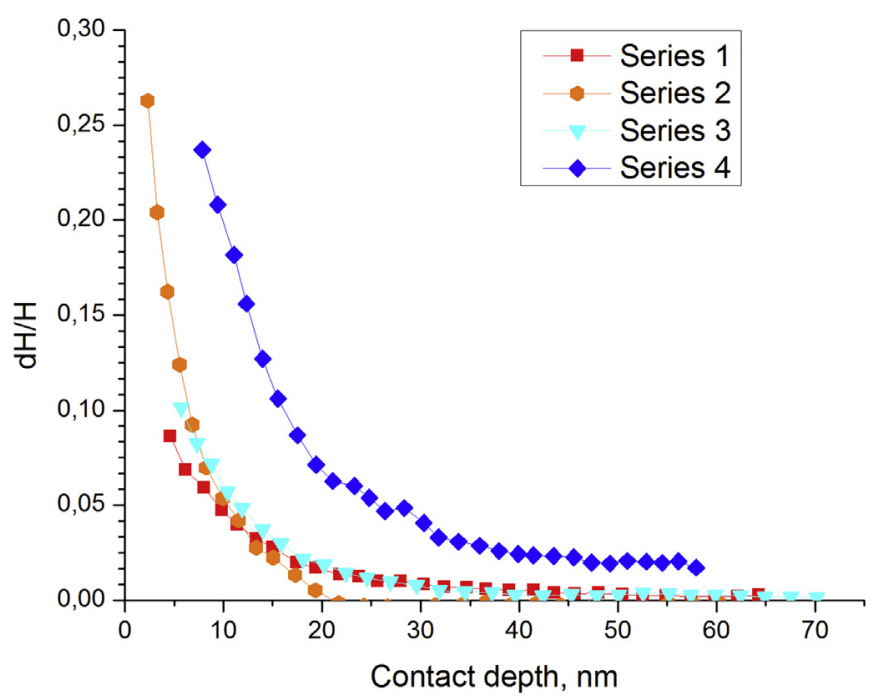

Fig. 9. Dependencies of relative hardness $\mathrm{dH} / \mathrm{H}$ on contact depth.
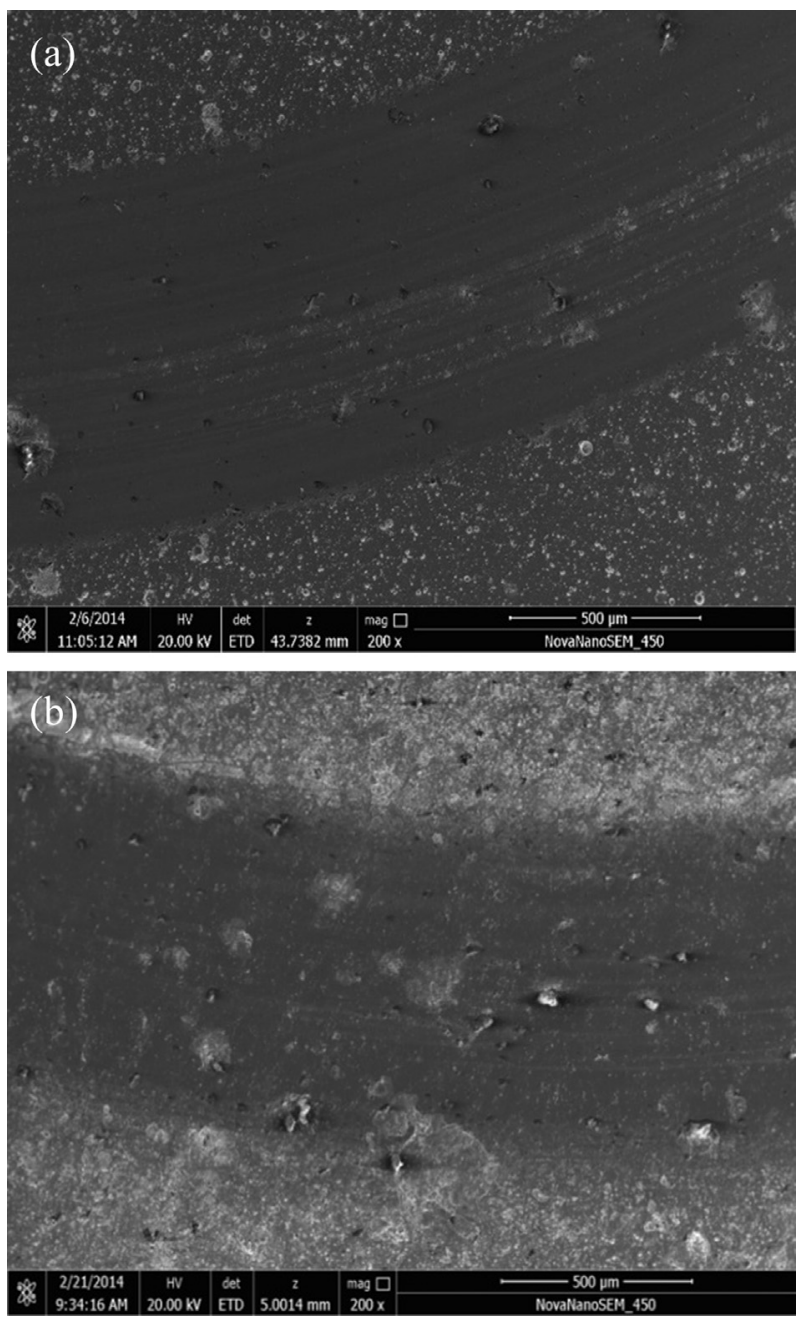

Fig. 10. Images of wear tracks in the samples from Series 2 (a), Series 3 (b).

the Series 6 - indentation of the Berkovich pyramid under dynamic loading as well as 2D and 3D images of the stamp, from which we can estimate the depth of the indentation and determine the value of the reduced elasticity modulus. The loading on the indenter varied in the range $500 \mu \mathrm{N}$ до $10000 \mu \mathrm{N}$. On the graph one can see dynamic "load-unload" cycles.

The dependencies of relative nanohardness $\mathrm{dH} / \mathrm{H}$ on indenters' penetration depth are presented on the Fig. 9. It is clearly seen, that the highest values of hardness are observed in the implanted layer (up to $25 \mathrm{~nm}$ ), and when values of nanohardness are at the stable level. Increasing of nanohardness is not so significant for nonimplanted coatings, but takes place approximately at the same depth (up to $20 \mathrm{~nm}$ ). The Series 4 demonstrates other tendencies, due to its better mechanical characteristics, in comparison with other non-implanted series.

Conclusion regarding improvement of wear resistance of investigated coatings, based on $\mathrm{H} / \mathrm{E}$ ratio, is also supported by tribological measurements of coating's wear. On the Fig. 10 (a, b) wear tracks are presented. On the Fig. 11 we present a plot of friction coefficient changes during measurements for the coating of Series 2 . We can see that coatings did not lose integrity and did not wear down to substrate, it confirm its enhanced resistance to wear. Preliminary scratch-tests on the samples implanted by $\mathrm{Au}^{-}$(dose was $10^{17} \mathrm{~cm}^{2}$ ) showed significant decreasing of the friction coefficient values from 0.75 to 0.243 in the first 320 s of friction, and then 


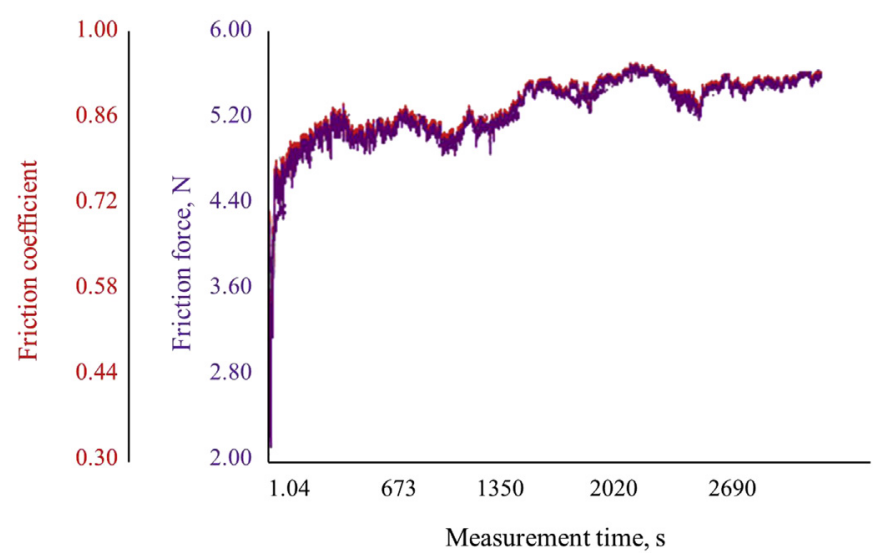

Fig. 11. Results of tribological tests (friction coefficient) of the (TiZrNbHfVTa)N coating, sample from the Series 2 .

it increased to 0.78 during the next 1000 s. From Fig. 11 we can see that friction coefficient significantly increased to the values $0.8-0.92$ in the beginning of measurements, and then it was still not stable. It can be explained by the features of coating's relief.

\section{Conclusions}

It has been shown, that deposition parameters affected the element composition, surface morphology and phase structure of the nitride high-entropy coatings (TiHfZrNbVTa)N. Increasing of working gas pressure led to resputtering of heavy elements, and domination of FCC crystalline phase in the coating. Thus, obtained coatings' structure changes from amorphous (for low gas pressure) to nanocrystalline (for higher $\mathrm{N}_{2}$ pressure), which directly defines its properties.

Negative heavy-ion implantation of $\mathrm{Au}^{-}$ions led to selective sputtering of nitrogen atoms, and it caused increasing of relative ratio of BCC-phase in the coatings, as it was determined by XRD analysis. Implanted surface area had polycrystalline structure, without preferred orientation. Investigation of mechanical properties showed, that ion implantation led to improving of mechanical properties of the coatings due to structure changes in the material under ion irradiation. Thus, we can conclude, that investigated multielement nitride coatings (TiHfZrNbVTa)N demonstrated irradiation resistance, what makes them perspective in terms of using in different branches of industry, particularly nuclear and chemical.

\section{Acknowledgements}

This work was done under the aegis of Ukrainian complex state budget programs "Development of material science foundations of structure engineering of vacuum-plasma superhard coatings with required functional properties" (registration number 0115U000682) and "Physical principles of plasma technologies for complex treatment of multicomponent materials and coatings" (registration number 0113U000137c). The authors are grateful to Prof. Oleg Sobol for his participation in the discussing of the XRD and TEM results, as well as to A.V. Pshyk for his help in nanohardness measurements and to U.S. Nemchenko for her participation in wear experiments. The authors are also grateful to Prof. Stefan Jurga from NanoBioMedical Centre, Adam Mickiewicz University (Poznan, Poland) for the opportunity to provide some investigations in the Centre.

\section{References}

[1] B.R. Braeckman, F. Boydens, H. Hidalgo, P. Dutheil, M. Jullien, A.-L. Thomann, et al., High entropy alloy thin films deposited by magnetron sputtering of powder targets, Thin Solid Films 580 (2015) 71-76, http://dx.doi.org/10.1016/ j.tsf.2015.02.070.

[2] A.D. Pogrebnjak, Structure and properties of nanostructured (Ti-Hf-Zr-V-Nb)N coatings, J. Nanomater. 2013 (2013) 1-12, http://dx.doi.org/10.1155/2013/ 780125.

[3] S.R.B.S. Murty, J.W. Yeh, High-Entropy Alloys, Butterworth-Heinemann, 2014. http://store.elsevier.com/High-Entropy-Alloys/B_S_-Murty/isbn9780128002513/.

[4] Y. Zhang, T.T. Zuo, Z. Tang, M.C. Gao, K.A. Dahmen, P.K. Liaw, et al., Microstructures and properties of high-entropy alloys, Prog. Mater. Sci. 61 (2014) 1-93, http://dx.doi.org/10.1016/j.pmatsci.2013.10.001.

[5] C.M. Liu, H.M. Wang, S.Q. Zhang, H.B. Tang, A.L. Zhang, Microstructure and oxidation behavior of new refractory high entropy alloys, J. Alloys Compd. 583 (2014) 162-169, http://dx.doi.org/10.1016/j.jallcom.2013.08.102.

[6] N.D. Stepanov, D.G. Shaysultanov, G.A. Salishchev, M.A. Tikhonovsky, E.E. Oleynik, A.S. Tortika, et al., Effect of V content on microstructure and mechanical properties of the CoCrFeMnNiVx high entropy alloys, J. Alloys Compd. 628 (2015) 170-185, http://dx.doi.org/10.1016/j.jallcom.2014.12.157.

[7] N.D. Stepanov, D.G. Shaysultanov, G.A. Salishchev, M.A. Tikhonovsky, Structure and mechanical properties of a light-weight AlNbTiV high entropy alloy, Mater. Lett. 142 (2015) 153-155, http://dx.doi.org/10.1016 j.matlet.2014.11.162.

[8] O.N. Senkov, S.V. Senkova, D.B. Miracle, C. Woodward, Mechanical properties of low-density, refractory multi-principal element alloys of the $\mathrm{Cr}-\mathrm{Nb}-\mathrm{Ti}-\mathrm{V}-\mathrm{Zr}$ system, Mater. Sci. Eng. A 565 (2013) 51-62, http:// dx.doi.org/10.1016/j.msea.2012.12.018.

[9] S. Veprek, Recent search for new superhard materials: go nano!, J. Vac. Sci. Technol. A Vac. Surfaces, Film 31 (2013) 050822, http://dx.doi.org/10.1116/ 1.4818590 .

[10] T.N. Koltunowicz, P. Zukowski, V. Bondariev, J.A. Fedotova, A.K. Fedotov, The effect of annealing on induction like properties of (FeCoZr)x(CaF2)(100-x) nanocomposite films produced by ion-beam sputtering in the vacuum environment, Vacuum 120 (2015) 44-50, http://dx.doi.org/10.1016/ j.vacuum.2015.01.030.

[11] T.N. Koltunowicz, P. Zhukowski, V. Bondariev, A. Saad, J.A. Fedotova, A.K. Fedotov, et al., Enhancement of negative capacitance effect in (CoFeZr) $\mathrm{x}(\mathrm{CaF} 2)(100-\mathrm{x})$ nanocomposite films deposited by ion beam sputtering in argon and oxygen atmosphere, J. Alloys Compd. 615 (2014) S361-S365, http://dx.doi.org/10.1016/j.jallcom.2013.12.125.

[12] I. Svito, J.A. Fedotova, M. Milosavljević, P. Zhukowski, T.N. Koltunowicz, A. Saad, et al., Influence of sputtering atmosphere on hopping conductance in granular nanocomposite (FeCoZr)x(Al2O3)1-x films, J. Alloys Compd. 615 (2014) S344-S347, http://dx.doi.org/10.1016/j.jallcom.2013.12.061.

[13] S. Veprek, M.G.J. Veprek-Heijman, P. Karvankova, J. Prochazka, Different approaches to superhard coatings and nanocomposites, Thin Solid Films 476 (2005) 1-29, http://dx.doi.org/10.1016/j.tsf.2004.10.053.

[14] S.S.G.V.P. Pichugin, A.A. Pustovalova, M.E. Konishchev, I.A. Khlusov, N.M. Ivanova, Sun zhilei, in-vitro dissolusion and structural and electrokinetic characteristics of titanium-oxynitride coatings formed via reactive magnetron sputtering, J. Surf. Investig. X-Ray, Synchrotron Neutron Tech. 10 (2016) 282-291.

[15] I.A. Lyashenko, A.M. Zaskoka, Taking into account the universal dependence of the viscosity of a boundary lubricant on temperature and strain rate to describe stop-start experiments, Tech. Phys. 60 (2015) 1014-1020, http:// dx.doi.org/10.1134/S1063784215070178.

[16] B. Ren, Z. Shen, Z. Liu, Structure and mechanical properties of multi-element (AlCrMnMoNiZr)Nx coatings by reactive magnetron sputtering, J. Alloys Compd. 560 (2013) 171-176, http://dx.doi.org/10.1016/j.jallcom.2013.01.148.

[17] D.-C. Tsai, Y.-L. Huang, S.-R. Lin, S.-C. Liang, F.-S. Shieu, Effect of nitrogen flow ratios on the structure and mechanical properties of (TiVCrZrY)N coatings prepared by reactive magnetron sputtering, Appl. Surf. Sci. 257 (2010) 1361-1367, http://dx.doi.org/10.1016/j.apsusc.2010.08.078.

[18] K.-H. Cheng, C.-H. Lai, S.-J. Lin, J.-W. Yeh, Structural and mechanical properties of multi-element (AlCrMoTaTiZr)Nx coatings by reactive magnetron sputtering, Thin Solid Films 519 (2011) 3185-3190, http://dx.doi.org/10.1016/ j.tsf.2010.11.034.

[19] V. Braic, A. Vladescu, M. Balaceanu, C.R. Luculescu, M. Braic, Nanostructured multi-element (TiZrNbHfTa)N and (TiZrNbHfTa)C hard coatings, Surf. Coatings $\begin{array}{llll}\text { Technol. } 211 \quad \text { (2012) 117-121, http://dx.doi.org/10.1016/ } & \end{array}$ j.surfcoat.2011.09.033.

[20] V. Ivashchenko, S. Veprek, A. Pogrebnjak, B. Postolnyi, First-principles quantum molecular dynamics study of Ti x Zr 1- x N(111)/SiN y heterostructures and comparison with experimental results, Sci. Technol. Adv. Mater. 15 (2014) 025007, http://dx.doi.org/10.1088/1468-6996/15/2/025007.

[21] A.A. Goncharov, Mechanism of formation of the columnar structure in films of transition metal diborides, Phys. Solid State 50 (2011) 168-172, http:/ dx.doi.org/10.1134/S1063783408010307.

[22] A.D. Pogrebnyak, A.P. Shpak, N.A. Azarenkov, V.M. Beresnev, Structures and properties of hard and superhard nanocomposite coatings, Physics-Uspekhi 52 (2009) 29-54, http://dx.doi.org/10.3367/UFNe.0179.200901b.0035. 
[23] A.V. Khomenko, I.A. Lyashenko, V.N. Borisyuk, Self-similar phase dynamics of boundary friction, Ukr. J. Phys. 54 (2009) 1139-1148. http://www.scopus. com/inward/record.url?eid=2-s2.0-70749119448\&partnerID=tZOtx3y1.

[24] A.D. Pogrebnjak, A.P. Shpak, G.V. Kirik, N.K. Erdybaeva, M.V. Il'yashenko, A.A. Dem'Yanenko, et al., Multilayered nano-microcomposite Ti-Al-N/TiN/ Al203 coatings. Their structure and properties, Acta Phys. Pol. A (2011) 94-99. http://www.scopus.com/inward/record.url?eid=2-s2.079957873020\&partnerID=tZOtx3y1.

[25] A.D. Pogrebnjak, A.M. Tolopa, A review of high-dose implantation and production of ion mixed structures, Nucl. Instrum. Methods Phys. Res. Sect. B Beam Interact. Mater. Atoms 52 (1990) 25-43, http://dx.doi.org/10.1016/ 0168-583X(90)90598-0.

[26] Fadei Komarov, Ion Beam Modification of Metals, Gordon and Breach Science Publishers, 1992. https://openlibrary.org/works/OL3145206W/Ion_beam_ modification_of_metals.

[27] V.I. Lavrentiev, A.D. Pogrebnjak, High-dose ion implantation into metals, Surf Coatings Technol. 99 (1998) 24-32, http://dx.doi.org/10.1016/S02578972(97)00122-9.

[28] O.M. Ivasishin, A.D. Pogrebnjak, S.N. Bratushka, Nanostructured Layers and Coating Formed by Ion-plasma Fluxes in Titanium Alloys and Steels, Akademperiodyka, Kyiv, 2011.

[29] A.D. Pogrebnjak, S.N. Bratushka, V.M. Beresnev, N. Levintant-Zayonts, Shape memory effect and superelasticity of titanium nickelide alloys implanted with high ion doses, Russ. Chem. Rev. 82 (2013) 1135-1159, http://dx.doi.org/ 10.1070/RC2013v082n12ABEH004344.

[30] D.P. Datta, Y. Takeda, H. Amekura, M. Sasase, N. Kishimoto, Controlled shape modification of embedded Au nanoparticles by $3 \mathrm{MeV}$ Au2+-ion irradiation, Appl. Surf. Sci. 310 (2014) 164-168, http://dx.doi.org/10.1016/ j.apsusc.2014.03.121.

[31] A.V. Pshyk, L.E. Coy, L. Yate, K. Załęski, G. Nowaczyk, A.D. Pogrebnjak, et al., Combined reactive/non-reactive DC magnetron sputtering of high temperature composite AlN-TiB2-TiSi2, Mater. Des. 94 (2016) 230-239, http:// dx.doi.org/10.1016/j.matdes.2015.12.174.

[32] I.V. Lopatin, Y.K. Akhmadeev, N.N. Koval, P.M. Schanin, Plasma generation in a low-pressure hollow-cathode non-self-sustained glow discharge, High. Temp. Mater. Process. An. Int. Q. High-Technology Plasma Process 17 (2013) 117-125, http://dx.doi.org/10.1615/HighTempMatProc.2015013717.

[33] Y.K. Akhmadeev, P.M. Schanin, N.N. Koval, Plasma source with a cold hollow cathode based on arc discharge, High. Temp. Mater. Process. An. Int. Q. HighTechnology Plasma Process 17 (2013) 127-135, http://dx.doi.org/10.1615/ HighTempMatProc.2015013718.

[34] O. Krysina, Y.F. Ivanov, I.M. Goncharenko, M.I. Lobach, G.A. Pribytkov, I.A. Andreeva, et al., Synthesis of nanostructured nitride coatings by vacuum arc evaporation of sintered Ti-Al cathodes, High. Temp. Mater. Process. An. Int Q. High-Technol. Plasma Process 17 (2013) 153-160, http://dx.doi.org/ 10.1615/HighTempMatProc.2015013754.

[35] F.F. Komarov, V.M. Konstantinov, A.V. Kovalchuk, S.V. Konstantinov,
H.A. Tkachenko, The effect of steel substrate pre-hardening on structural, mechanical, and tribological properties of magnetron sputtered TiN and TiAlN coatings, Wear 352-353 (2016) 92-101, http://dx.doi.org/10.1016/ j.wear.2016.02.007.

[36] A.D. Pogrebnjak, D. Eyidi, G. Abadias, O.V. Bondar, V.M. Beresnev, O.V. Sobol, Structure and properties of arc evaporated nanoscale TiN/MoN multilayered systems, Int. J. Refract. Met. Hard Mater. 48 (2015) 222-228, http://dx.doi.org/ 10.1016/j.ijrmhm.2014.07.043.

[37] S.N. Bratushka, M. Opielak, S. Liscak, Structure and properties of Co-Cr coatings after a pulsed jet treatment, Prz. Elektrotechniczny 88 (2012) 314-318. http://www.scopus.com/inward/record.url?eid=2-s2.084867221149\&partnerID=tZOtx3y1.

[38] A.D. Pogrebnjak, I.V. Yakushchenko, G. Abadias, P. Chartier, O.V. Bondar, V.M. Beresnev, et al., The effect of the deposition parameters of nitrides of high-entropy alloys (TiZrHfVNb)N on their structure, composition, mechanical and tribological properties, J. Superhard Mater. 35 (2013) 356-368, http:/| dx.doi.org/10.3103/S106345761306004X.

[39] A.D. Pogrebnjak, A.A. Bagdasaryan, I. V Yakushchenko, V.M. Beresnev, The structure and properties of high-entropy alloys and nitride coatings based on them, Russ. Chem. Rev. 83 (2014) 1027-1061, http://dx.doi.org/10.1070/ RCR4407.

[40] A.D. Pogrebnjak, I.V. Yakushchenko, A.A. Bagdasaryan, O.V. Bondar, R. KrauseRehberg, G. Abadias, et al., Microstructure, physical and chemical properties of nanostructured $(\mathrm{Ti}-\mathrm{Hf}-\mathrm{Zr}-\mathrm{V}-\mathrm{Nb}) \mathrm{N}$ coatings under different deposition conditions, Mater. Chem. Phys. 147 (2014) 1079-1091, http://dx.doi.org/ 10.1016/j.matchemphys.2014.06.062.

[41] A.D. Pogrebnjak, I.V. Yakushchenko, O.V. Bondar, O.V. Sobol', V.M. Beresnev, $\mathrm{K}$. Oyoshi, et al., Influence of implantation of $\mathrm{Au}-$ ions on the microstructure and mechanical properties of the nanostructured multielement (TiZrHf VNbTa)N coating, Phys. Solid State 57 (2015) 1559-1564, http://dx.doi.org/ 10.1134/S1063783415080259.

[42] A.D. Pogrebnjak, I.V. Yakushchenko, O.V. Sobol', V.M. Beresnev, A.I. Kupchishin, O.V. Bondar, et al., Influence of residual pressure and ion implantation on the structure, elemental composition, and properties of (TiZrAlYNb)N nitrides, Tech. Phys. 60 (2015) 1176-1183, http://dx.doi.org/ 10.1134/S1063784215080228.

[43] N.I. Poliak, V.M. Anishchik, N.G. Valko, C. Karwat, C. Kozak, M. Opielak, Mechanical properties of $\mathrm{Zn}-\mathrm{Ni}$-SiO_2 coating deposited under X-ray irradiation, Acta Phys. Pol. A 125 (2014) 1415-1417, http://dx.doi.org/10.12693/ APhysPolA.125.1415.

[44] G.V. Kirik, C. Kozak, M. Opielak, Protective coatings based on Zr-Ti-Si-N their physical and mechanical properties and phase composition, Prz. Elektrotechniczny 88 (2012) 319-321. http://www.scopus.com/inward/record. url?eid=2-s2.0-84867220104\&partnerID=tZOtx3y1.

[45] J. Musil, Hard nanocomposite coatings: thermal stability, oxidation resistance and toughness, Surf. Coatings Technol. 207 (2012) 50-65, http://dx.doi.org/ 10.1016/j.surfcoat.2012.05.073. 